\title{
A View of Computer-Supported Collaborative Learning Research Today
}

\author{
Gerry Stahl
}

\begin{abstract}
This is a review of research on educational technology from a particular historical and theoretical perspective. It focuses on the research field of computer-supported collaborative learning (CSCL) and does so based on the author's personal experiences in that field. Starting with an overview of the changing role of technology in educational design, it then looks at the shifting function of individual learning as a component of group collaboration, with the central theme of intersubjectivity. The multiple dimensions of philosophical and analytic perspectives that emerged in the past have spawned a variety of methodological and thematic alternatives in current research. Lessons learned from this research point to a number of principles for productive, multi-disciplinary research in the future, as the field of CSCL spreads globally.
\end{abstract}

\section{Introduction}

The research field of computer-supported collaborative learning (CSCL) has grown rapidly to incorporate a broad spectrum of approaches. Since the first CSCL conference in 1995, many people have made contributions to the field in strikingly diverse ways. Although most researchers in the past came from Western European or North American universities, people are increasingly coming with other backgrounds and bringing new perspectives with them. In this paper, I would like to provide a conceptual and historical perspective on the CSCL field in order to suggest where I think things may be heading and to get a sense of what I feel may be needed now. A rule of thumb in cognitive science is that it takes a decade for a person to become an "expert" in a field - as the CSCL community becomes truly global, it may be even more challenging for CSCL researchers in parts of the world less familiar with the traditions that have become embodied in CSCL. The interdisciplinary field of CSCL is particularly multi-faceted and fast changing, which makes expertise as a CSCL researcher-or perhaps, more realistically, as a leading-edge CSCL research lab-a moving target, requiring a mixture of intellectual backgrounds and skills as well as constant learning, innovation and growth. The purpose of this paper is to suggest the limitations of superficial approaches and to provide pointers into the literatures that inform a nuanced understanding of the nature of research in CSCL and of the major issues confronting the field.

\section{Past: The Roots of CSCL}

\section{Schematic histories of educational technology}

To understand the current state of research in educational technology, it is important to place it in its evolving historical context. This involves the histories of education, theory, computer technology, software design and educational applications. (For a general introduction to CSCL translated into several languages, see (Stahl, 2010).) 
The history of education: The reconceptualization of learning from the transfer of facts to the ability to communicate understanding.

- The organization of education around the disciplines of the sciences and liberal arts;

- The provision of universal public education; the ideals of progressive education (Dewey \& Bentley, 1949/1991);

- The emphasis on creative exploration (Neill, 1960);

- Small-group cooperative learning;

- Project-based learning;

- Problem-based learning (Barrows, 1994);

- Collaborative learning and CSCL.

The history of theory: The unit of analysis of cognition expanded from the individual mind (Stahl, 2011b) (see Figure 1).

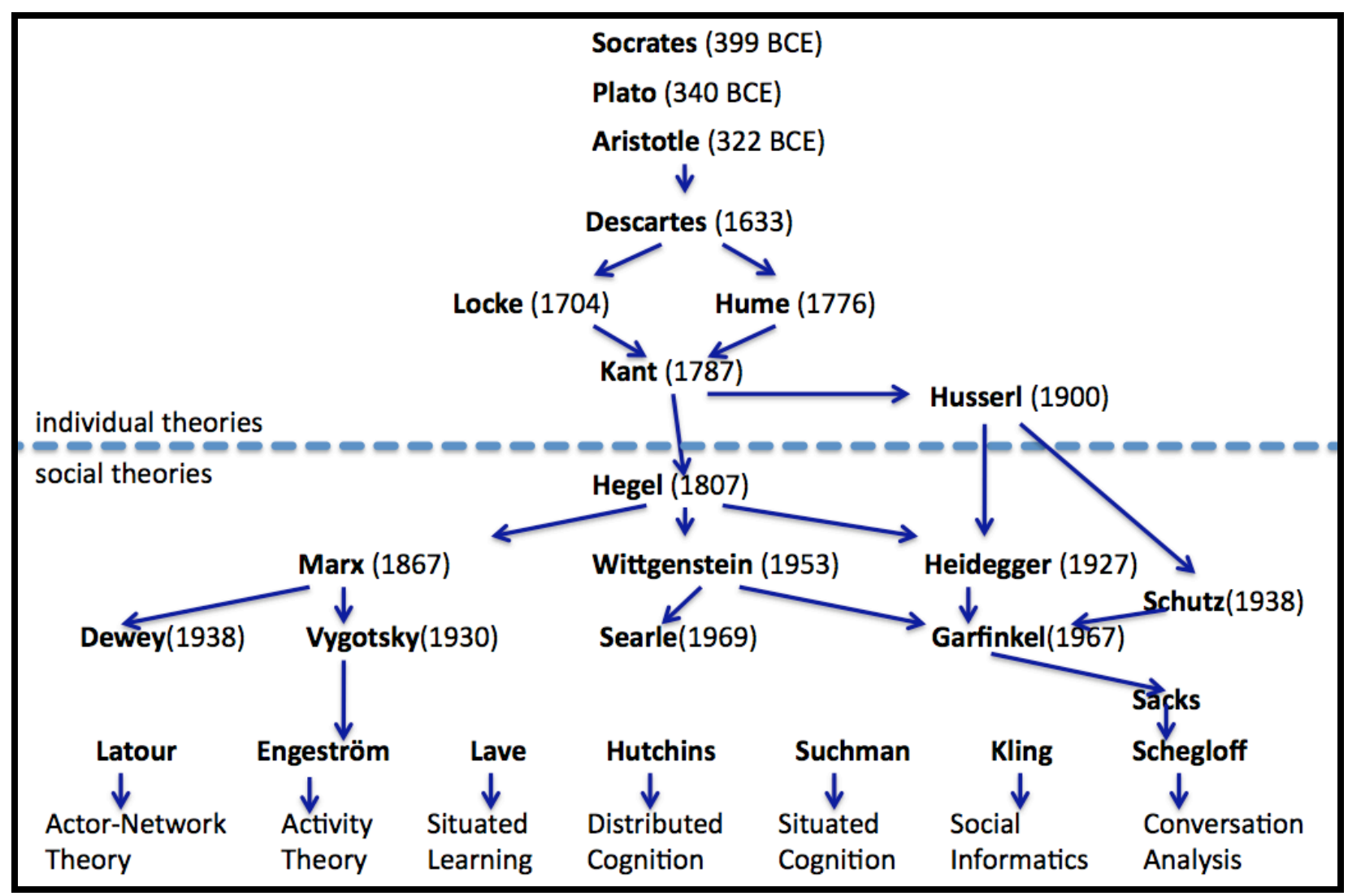

Figure 1 . The history of theory and the transition from the individual unit of analysis to post-cognitive theories. From (Stahl, 2011b).

- Philosophies of idealism, rationalism, empiricism;

- Behaviorism, cognitive science, situated and distributed cognition.

The history of computer technology: Technology spread from isolated machines to social infrastructures.

- Mainframe system software;

- Custom applications for corporations; 
- Generic desktop applications;

- Computer networking and groupware;

- Small apps for devices;

- Social networking media, cloud and ubiquitous computing.

The history of software design: Design expanded to stress how technology would be enacted, adopted, disseminated and used in practice (Landauer, 1996).

- Techno-centric design;

- Ergonomics and human factors;

- Human-centered design;

- Design-based research;

- Social informatics;

- Socio-technical design.

The history of educational applications: Support for learning expanded from focus on individuals acquiring facts to communities building knowledge (Koschmann, 1996a).

- 1950s: Cooperative learning in small groups (Johnson \& Johnson, 1989);

- 1960s: Computer-assisted instruction (e.g., arithmetic drill);

- 1970s: Intelligent tutoring systems (user modeling algebra misconceptions);

- 1980s: Logo as Latin (Papert, 1980);

- 1990s: CSCL (e.g., CSILE).

\section{The roles of technology in CSCL}

There is a natural tendency for people to think of opportunities that arise from new technologies in purely technical terms. We have seen this in our historical reviews. People tried to design technologies in terms of technical issues and their solutions failed to be adopted and used because social factors had not been taken into account as central design concerns. I see it all the time still, when a student-particularly one trained in a technical field - has an idea based on some technical possibility and proceeds to design something without investigating the human and social considerations. While it is natural to take such an approach, history has taught us over and over that this is a deeply flawed approach that will meet unforeseen problems and will not succeed no matter how good the idea seems on purely technical grounds.

Of course, software technology necessarily plays a central role in CSCL research. Researchers need to take software prototypes into classrooms and to conduct laboratory experiments that try out new ideas and get real-world feedback as correctives to their assumptions. But even beyond that, innovative software concepts - at least sketched out in designs, mock-ups and prototypes-are crucial for inspiring researchers, potential funding sources and future users like teachers and students. No one knows yet what future CSCL applications will look like and what kinds of features they will provide for learners or teams of knowledge builders. We need creative visions, programmed as software running on digital devices in order for people to even begin to think about how they might be used.

Technology is undeniably important to CSCL. The whole field is based on the potential of networked computers to bring together learners in ways that were not previously possible. But simply connecting people is not enough. The medium of connection must be carefully designed, studied, tested, analyzed, refined and re-designed to match educational and social settings and constraints. These requirements 
cannot be treated as an afterthought after the basic technology is already developed - for instance by adding a pretty user interface. The technology must be selected and designed from the start to meet nontechnical requirements. This will probably require the involvement in some fashion of potential users throughout the design and development process.

Technological advances will, of course, continue to inspire CSCL innovations. But this cannot successfully be done in a predominantly techno-centric manner. Innovation will have to be equally inspired by educational goals and by attempts to improve communication among people through the use of technology. For instance, the technical choice of a text chat medium versus a discussion forum may depend upon an educational scenario (e.g., brainstorming among small groups in a classroom period or long-term research within a globally distributed team) and social considerations (e.g., whether the participants can find desirable communication partners and concentrate on intense interaction at a specific time).

\section{The role of individual student learners in CSCL}

Another natural tendency is to design for learning by individual students. The usual concept of learning involves an increase in knowledge by an individual mind. This is the traditional conception in educational theory-based on common-sense (or folk-theory) assumptions. Although increased knowledge in general can include bodily capabilities, tacit skills or deeper understanding, within education it is generally taken to mean additional factual knowledge that can be expressed in explicit responses to tests.

CSCL is concerned with promoting collaborative learning-learning that takes place in small groups or classrooms of students. In the 1950s and 1960s, research on "cooperative learning" explored how small groups of students learned together. It investigated small-group dynamics and how to structure educational group processes. However, it did not conceive of learning as a group process, but rather looked at the individual learning that took place in the context of small-group activities (Johnson \& Johnson, 1989). This was the same approach taken by most small-group research in psychology and sociology, even today. CSCL, in contrast, is interested in collaboration (where students build knowledge together) more than cooperation (where group participants divide up tasks and than share each other's ideas) (Dillenbourg, 1999).

This distinction between cooperation of individuals and collaboration of a group defines a major divide in the theoretical frameworks within the CSCL field. Sfard (1998) expressed this divide as a contrast between the "acquisition metaphor" and the "participation metaphor." By acquisition metaphor, she meant the view that individual minds acquire knowledge; by the participation metaphor she meant the view that individuals participate in groups or communities that build knowledge. In the first, the unit of analysis, level of description or subject of agency is the individual student; in the second, it is the group. In her later detailed book on the cognition involved in learning mathematics, Sfard (2008) argued that thinking is fundamentally a communication process, and so it takes place within groups and communities more basically than in individual minds (for a review of this book, see Stahl, 2008).

I have developed the view that the group should be the primary unit of analysis for CSCL research in my theory of group cognition (Stahl, 2006). This view is difficult for most people to accept and consider because our common-sense assumptions about thinking are deeply ingrained. I have spent years trying to come to terms with this view myself, largely by writing about group cognition and exploring it in my research data. Most people try to reduce group-cognitive results to "underlying" individual mental constructs. But as we will see later in this paper, the most influential theories for CSCL argue that the individual mind is itself a social product, the result of ones interactions with parents, friends, colleagues, small groups and communities. Not only are individual mental practices derived from interpersonal and community practices, but there are also group knowledge-building processes that are distinct from and not reducible to individual mental processes (Hutchins, 1996). 
Of course, a group can only build knowledge with the participation of individuals, who must use their individual powers of understanding and communication. So the cognitive work of individuals, small groups and communities in collaborative learning are inseparable and complexly intertwined (Rogoff, 1995). Whereas other fields are primarily concerned with individual learning and community knowledge building, CSCL must be specifically concerned with supporting the small-group processes and the integration of individual, group and community processes. While specific research projects may have to focus on one of these units of analysis, the CSCL research community as a whole will need to understand all the levels and their interrelationships.

\section{The role of testing and assessment in CSCL}

The traditional conception of learning as an increase in the ability of an individual to express knowledge in the form of propositions has lead to the prominence of testing of factual knowledge by individual students. An over-emphasis on testing in schools lessens the motivation of teachers to use collaborative learning approaches and causes students to compete for grades rather than collaborate with their peers for knowledge. It promotes the ideology of individualism and the culture of competition, preparing young people for the former age of industrial capitalism. But in the global, networked economy of the $21^{\text {st }}$ Century, skills and values of teamwork and collaboration are essential; new forms of assessment are needed that support that (Lee, Chan \& van Aalst, 2006).

The ideology of individualism has had implications for educational research. The traditional experimental paradigm involves measuring changes in individual knowledge between a pre-test and a post-test. In many cases, the researcher establishes two or more experimental conditions and then codes events based on a pre-conceived scheme of categories. The statistical differences between the codes of the different conditions are then correlated with the increases in the test scores of students in the corresponding conditions to provide evidence that the difference in the conditions contributed to learning. For instance, if a new educational software application was used in one condition and not in the other, then an increase in the test scores of students who used the software would be taken as validation of the software's educational value and significant differences in the codes of the conditions might indicate causal factors.

There are a number of limitations of this research approach, despite its usefulness in certain circumstances. By relying on a given set of coding categories, it limits itself to a preconceived conceptualization (theory) and cannot discover other factors. Furthermore, although it can measure correlations, it does not provide insight into how learning mechanisms take place. Statistical analyses rely on large numbers of data points in order to average over individual differences; particularly for experiments with small groups - where there are learning effects within the groups as well as between individuals - the number of necessary cases is generally unpractical (Cress, 2008). Most educational experiments of this type result in no significant findings (Russell, 1999).

As discussed below, it is generally more effective to assess educational interventions with innovative software using a mixture of analysis approaches, including case studies that try to understand the meaning making that takes place within small groups. I have used interaction analysis (Jordan \& Henderson, 1995) techniques to identify some of the processes that groups use to make meaning (Stahl, 2006) and build knowledge together (Stahl, 2009). These studies can provide insight into computer-supported collaborative learning by following the sequential flow of student utterances responding to each other in the logs of their interactions (Stahl, 2011a). Because the students are problem solving together, they necessarily express their individual thinking to each other and this is available to analysts in the logs. In addition, the group stream of proposals, responses, questions, agreements, etc. is available for analysis as an extended cognitive process. The conversation analysis focuses on the sequential nature of the thinking, which is lost in most statistical coding analyses.

Perhaps the most interesting problem with focusing on the individuals when analyzing or assessing collaborative learning is related to the paradox of "productive failure" (Barron, 2003; Kapur \& Kinzer, 
2009; Pathak et al., 2011; Schwartz, 1995). The phenomenon of productive failure is a significant discovery in the CSCL literature. It consists of the finding that small groups that show less learning in the short term sometimes reveal more - and deeper-learning in the long run. It seems that these groups take time to develop a more abstract understanding of the problem they are working on and that this extra group-cognitive effort detracts from their ability to score well on their immediate tasks-relative to groups that just follow standard procedures to get answers without trying to understand the deeper issues. However, the abstract understanding gained by the "failure" groups gives them an advantage when facing challenging tasks in the future. The effect carries over to the individuals in the groups, so that the test scores of the individuals from the groups with the deeper understanding may score poorly on the immediate test, but best on future tests. This seems to provide a strong argument against the validity of traditional testing itself, for testing tends to reflect immediate results more than underlying learning.

The phenomenon of productive failure can be understood more generally in terms of Vygotsky's theory of the zone of proximal development (Vygotsky, 1930/1978). Vygotsky argues that individual learning is generally preceded by inter-personal learning. One learns initially by interacting with other people and then gradually (often over years) "internalizing" this learning into individual skills. Thus, it should not be surprising that students can accomplish tasks in small groups that they cannot duplicate immediately in individual tests, but that might be essential for their future abilities, which can show up in future tests.

This phenomenon has potential implications for assessment of individual and collaborative learning. Because students must make the thinking visible to each other in collaborative work, an instructor or an analyst with access to the logs of the group interactions can see quite clearly the level of understanding in the group, the contributions of specific individuals and the changes in understanding at both the group and individual levels. For instance, when I have students in my courses work on weekly assignments in online chats or discussions and then give group presentations to the rest of the class, the learning that is taking place is quite visible to me and there is no need to subject the students to standard forms of individual testing.

\section{The role of supporting intersubjective meaning making}

Given the central role of group cognition in CSCL settings, a major goal of educational software should be to support the group processes that foster intersubjective meaning making. It is not sufficient to provide factual knowledge and to motivate individual effort. It is also important to attract students to work together in effective groups, to provide appropriate communication media for their interaction, to offer tasks that stimulate interaction and require collaboration, to provide social awareness of what everyone is doing in the group interaction, to represent progress on the task in ways that help to conceptualize it, to display the group approach in a visual joint problem space and to document the accomplishments of the groups.

Intersubjectivity is central to the research field of CSCL. Although the concept has been mentioned occasionally in the history of philosophy and in the CSCL literature, it has never been clearly worked out. This should be a task of CSCL research and theory.

What is intersubjectivity? It is not a thing or an individual facility-although it relies on basic human linguistic and mental abilities (Gallese \& Lakoff, 2005). Intersubjectivity is the ability of people to understand each other. How is it that when one person in a group says, types or gestures other people in the group can understand what is meant? We need not speculate whether the meaning is "represented" the same way in each person's head; that may not be a meaningful question (Wittgenstein, 1953). The point is that the people can continue smoothly with their interaction, perhaps adding evidence that they share a joint understanding by their subsequent behavior. Clearly, sharing a language provides an extensive basis for intersubjectivity, because languages are enormous symbolic repositories of culturally transmitted meaning. Relatedly, we are socialized to interact with other people intersubjectively (see Figures 2 and 3 ). 

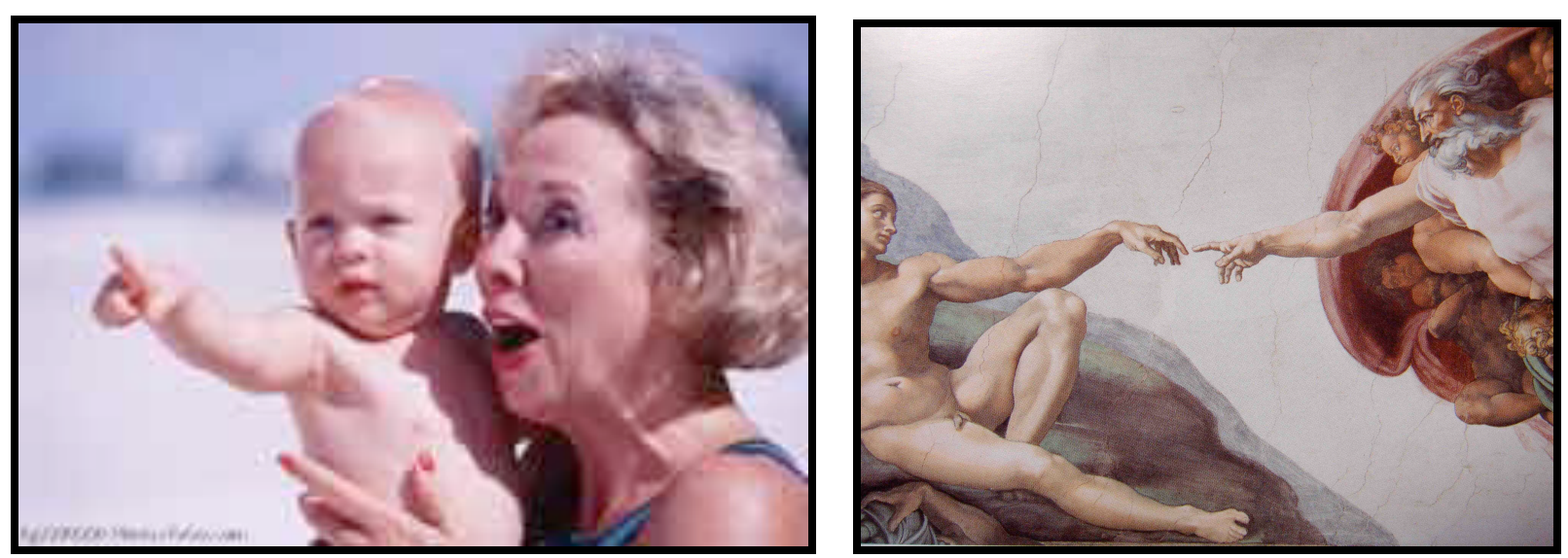

Figure 2. An infant and adult share a meaningful orientation in the world, mediated by pointing. Figure 3.

God and man share a meaningful gesture (excerpt from Michelangelo, the Sistine Chapel).

As Vygotsky points out in his analysis of an infant gesturing, the establishment of shared meaning provides the basis for our individual understanding of that meaning (Vygotsky, 1930/1978, p. 56). Fundamentally, intersubjectivity is grounded in our existing in a shared meaningful world (Heidegger, 1927/1996; Stahl et al., 2011). In addition, it is worked out constantly, as we interact with other people, repair misunderstandings, fill in new shared understandings and refine existing partial understandings. Careful analysis of logs of CSCL data can provide detailed analyses of intersubjectivity and its role in computer-supported collaborative learning. Such analysis, in turn, can suggest ways to improve computer support for intersubjectivity.

\section{Present: Alternative approaches within CSCL}

\section{The theoretical divide}

CSCL is a multidisciplinary field. This has the enormous advantage that it has applied to the complex problems of designing computer support for collaborative learning expertise and knowledge from the fields of computer science, education, psychology, communications, artificial intelligence and schoolsubject domains. However, it also has the consequence that researchers have brought with them to CSCL diverse and seemingly conflicting views of how to conduct science. This has often led to a feeling of "us" and "them" between groups of researchers-sometimes simplistically referred to as a choice between "quantitative" versus "qualitative" approaches to research. This divide is derived from a fundamental dichotomy in the larger scientific world.

Perhaps the most profound and innovative attempt to understand that dichotomy is the work of Habermas:

There are competing theoretical approaches in the social sciences that differ not only in the kinds of problems they address and the research strategies they apply, but in their fundamental principles. They diverge in their choice of categorical frameworks and in how they conceptualize their object domain - that is in how they define what it is they are actually studying. These differences of conceptual strategy express more deeply rooted conflicts: conflicting views of science and cognitive interests. (Habermas, 1971/2001, p. 3)

Habermas distinguishes approaches of social sciences in terms of three decisions:

1. Whether "meaning" is admitted as a primitive term.

2. Whether intentional action is conceptualized in the form of purposive-rational action or in the form of communicative action. 
3. Whether all social phenomena must be analyzable in the form of statements about the actions of individual subjects.

I would apply the first decision to research in CSCL by distinguishing two general paradigms, which I will refer to as the "objective paradigm" and the "meaningful paradigm." The objective paradigm has roots in positivist philosophy of natural science and in behaviorist social science, although it includes the critiques of these within cognitive science. The meaningful paradigm has roots in interpretive (verstehende) sociology and anthropology; it includes much of the situated-action critique of cognitivism. Adherents to the objective paradigm try to analyze their data objectively, without subjective interpretation of what the data meant for the subjects. For instance, they rely on objective pre- and post-tests to measure changes in student knowledge and manipulate experimental conditions. Quantitative statistical analyses confirm or disconfirm hypothesized patterns of effects for average subjects. Adherents of the meaningful paradigm try to understand the meaning expressed in their data, often by focusing in detail on the meaning-making processes in a specific case study.

Habermas makes the distinction (in the second decision) between purposive-rational action and communicative action-which he also calls "work" and "interaction" (Habermas, 1971). He argues that both are necessary. Purposive-rational action is our primary way of interacting with nature, controlling it to meet our needs by following strategic thinking. It is close to what Suchman (1987) calls "plans" in contrast to "situated action" and to what Dreyfus (1992) attributes to the rationalist tradition in Western philosophy, as opposed to tacit and embodied knowledge. But communicative action, or interaction, is fundamentally different from work; it is in the social and ethical realm of living with other people. It involves understanding, negotiation and intersubjectivity. Habermas believes that interaction assumes an ideal form of communication among unconstrained peers - an ideal that is never completely achieved. In practice, work and interaction are always intertwined, and matters of power or manipulation assert worktype strategies into communicative action, imposing systematic distortions. Within CSCL settings, we can see that students blend strategic goal-oriented work on their assigned tasks with social interaction with their peers. This takes place in school contexts filled with interpersonal and power relationships. CSCL research must also involve both purposive-rational action and communicative action, working on technological nature and interacting with students.

Habermas' third methodological decision relates to the unit of analysis and the ideology of individualism discussed above. Although many social sciences have tried to reduce social phenomena to actions of individuals, there are also holistic, ecological, functionalist and structuralist theories that do not. As we have seen, the history of theory has recently moved beyond the individual mind to post-cognitive theories of distributed and situated cognition.

\section{Dimensions of analysis}

In addition to the distinction between objective and meaningful stances toward CSCL data and toward the world, there are numerous other dimensions of approaches to analysis. For instance, in the temporal dimension one can look at very brief episodes of interaction or much longer, longitudinal studiesultimately over a lifetime or even generations, as learning and meaning are embedded in cultural artifacts and preserved.

As already indicated, the unit of analysis is critical; one can study actions and processes of individuals, small groups, classrooms, communities of practice or whole cultures.

From a socio-technical viewpoint, one can focus on technology options, features and approaches or one can consider how a software system will be enacted by its user community, how people will integrate it into their lives and workflow, how usage will be disseminated through communities and how the user community may drive future evolution of the application. 
As topics of investigation, one can study different learning issues like motivation, knowledge or efficiency. One can make comparisons based on learner characteristics, such as age, nationality, socioeconomic status. Of course, there are the different disciplines of learning-e.g., mathematics, argumentation, science, informal learning. And there are different pedagogical approaches to be supported: instructionist, exploratory, socio-cognitive, socio-cultural, knowledge acquisition or knowledge building. These different research directions may suggest different facilitating technologies: scripting, game-like applications, tabletop interfaces or mobile-device interactions, for instance.

\section{Multi-vocal methods}

Although there have been many differences of approach within CSCL research in the past, there seems to be a strong tendency among leading researchers in the present to converge. This is not happening by one approach winning out over others, but rather through a growing recognition of the power and even necessity of incorporating multiple approaches in exploring the design of educational applications. This shift has proceeded through a number of steps:

The first step was to reject any a priori commitment to a specific methodological approach - such as the one in which one may have been trained. The widely accepted rule of thumb now is that the approach should be selected based upon the nature of ones research interests, questions, hypotheses and data.

The second step was to recognize that a research agenda in CSCL will probably go through a sequence of phases and that different approaches are likely to be most productive in different phases. For instance, an informal exploratory approach might be appropriate to a pilot phase in which issues first emerge. Then a comparative statistical test might indicate which factors are most significant. Following that, a microanalytic case study could probe the processes and mechanisms that are behind the statistical findings. In addition, at any phase mixed methods can be used to triangulate views on the same phenomenon from different theoretical or methodological perspectives. It may then be necessary to iterate the whole sequence of phases multiple times as a software application and its pedagogical scenario are re-designed and refined.

The third step was to discover the complementarity of objective and meaningful analyses. Many researchers who started with one of these approaches realized as they articulated their findings that they needed evidence that could only come through the other approach. Just as people generally need both strategic actions in dealing with nature and communicative actions in interacting with people and just as CSCL as a field needs to address both technical and social issues, so a CSCL research project may need to conduct objective, controlled, statistical analyses and also careful interpretations of meaning-making processes.

The fourth step was to recognize the power of collaboration across research labs, including globally. By bringing together researchers from different traditions, collaborative research efforts have access to more theoretical viewpoints, methodological approaches, educational technologies and rich data sources. Of course, there are fundamental differences between different approaches and methods cannot be mixed indiscriminately. The issues in moving from an individual method to multivocality have yet to be resolved, even though the trend in that direction seems promising. The research questions that CSCL faces are complex and involve different aspects and components, which may be best analyzed by different methods. An investigation of meaning making in groups may benefit from an objective analysis of individual behaviors and vice versa-without denying the theoretical differences among the approaches. 


\section{Future: Lessons from CSCL Research and Theory}

\section{Lesson 1: Learn collaboratively in multi-disciplinary labs}

The consequences of the preceding discussion seem quite clear. While an individual researcher must focus on a specific, well defined project and must rely on his or her background, training and interests, significant contributions to CSCL are likely to continue to come from research collaborations, which span both disciplinary and theoretical boundaries. The myth that a lone programmer with a bright idea, working in an isolated garage can produce an application that will be significant is an illusion. Collaborate!

On the other hand, labs interested in educational technology desperately need highly skilled and creative software designers, developers and engineers. Commercial software-even software that claims to be for schools or education - is rarely adequate to meet the needs of creative researchers. Someone has to develop mock-ups and running prototypes to show researchers, teachers and students what is possible and to give them hands-on experience. This takes a technical understanding of the latest software possibilities and the ability to create innovative software. It is important, however, that the software developers understand the perspective of the other researchers and educators and can communicate effectively with them both ways: to understand their ideas and to explain the possibilities and limitations of the technology.

I learned how to collaborate most clearly in the Virtual Math Teams (VMT) Project (Stahl, 2009). This was a collaborative project with the Math Forum, an online resource site for mathematics students and teachers. The project team included a math educator (the director of the Math Forum and his staff), an anthropologist, an ethnomethodologist, four research assistants (from four different countries), a series of visiting researchers, software developers and myself. While a number of the researchers had backgrounds in computer science, we had to bring in a series of specialized developers to build, debug, re-design and launch the many versions of our software environment.

Over the years, we had several visiting researchers - mostly from Europe - who each stayed for three to six months. The first was an enthusiast of quantitative data analysis, who developed a multi-dimensional coding scheme for our data and trained us in the objective approach. The next was a statistician, who analyzed our initial codings. Then a dialogical researcher came and exposed us to Bakhtin's views. Other researchers helped to refine our software design or conducted studies using our data. We also encouraged international colleagues to run experiments with our software and to analyze our data in a variety of ways. For several years, we conducted weekly data sessions in which the team looked at data excerpts together-line by line-and discussed their meaning from our different viewpoints. Looking at the same data in this shared environment, we learned to see through each other's eyes.

\section{Lesson 2: Study different approaches to CSCL issues}

Learning all the theories, concerns and methods needed to conduct CSCL research is a daunting challenge. It helps to have a solid grounding in computer science, education, psychology, communications, artificial intelligence, philosophy, social science and school disciplines. Not many graduate students start with that, which is why they need to collaborate with others. But, in addition, newcomers to CSCL have to catch up on some of the classics of the field. To meet this need, I start my courses in CSCL with the following two slim books and three chapters from the CSCL edited volume (Koschmann, 1996b). The two books are truly seminal; they define the socio-cultural theory that is central to CSCL; they deserve to be read thoughtfully multiple times. The three chapters define the beginnings of CSCL as a field distinguished from educational technology more broadly conceived.

Vygotsky (1930/1978) - Developmental analysis; mediated cognition; intersubjective learning is primary; zone of proximal development shows group cognition becomes internalized as individual cognition, just 
as spoken communication becomes self-talk and then internal thought and as bodily gestures and material artifacts become psychological skills/resources/faculties.

Lave \& Wenger (1991) - Communities of practice, learning as legitimate peripheral participation.

Koschmann (1996a) - History of paradigms of educational technology.

Scardamalia \& Bereiter (1996) - Public expression, refinement of ideas, scientific community processes of publication, networked sharing of documents, guidance in scientific reflection.

Roschelle (1996) - Analysis of dialogical meaning making, shared understanding, external representation of joint problem space, conversation analysis.

\section{Lesson 3: Conduct design-based research}

Educational software is not created through a traditional software-development sequence of design, implement, debug, test, disseminate and then research impact. Rather, there is usually an on-going cyclical process of trying something out, seeing how it is used, responding to problems through re-design, testing alternative versions, etc. In other words, the different phases are tightly coupled and the designimplement-test-redesign cycle is repeated as frequently as possible. The software development and the educational research are interdependent. This is how most serious CSCL research is conducted. It is called design-based research because the research drives the design and the development work provides both opportunities and motivation for the research. In its richest form, the research process modifies the theory and the analysis methods along with the software applications and the pedagogical practices.

Again, I look at the VMT Project as an example of design-based research. We constantly modified the software and tried new features - often frustrating groups that were trying to use it. We had teachers try it in classrooms at various levels, from middle school (age 15) to junior college and graduate school. We ran math contests with students from around the world and encouraged other researchers to use it where they could. This supplied us with a continuing flow of feedback on our various versions and interventions. In some cases, informal reports from teachers and remarks from students were enough to guide redesign; in other cases, we studied student interactions in the VMT environment quite intensively-even basing doctoral dissertations on the interactions of a single group. We started with a generic chat app and a simple math problem and gradually evolved a complex collaboration environment for exploring mathematical relationships.

\section{Lesson 4: Engage in socio-technical design}

Because CSCL is a meeting place for collaborative learning and computer support, research in this field generally combines some exploration of technological media with an investigation of its use or adoption by students, teachers and/or school systems. Of course, a focused research paper might just report on one aspect of a larger research effort-perhaps a technical feature, a learning achievement or a theoretical conception. But these findings are likely to emerge from more inclusive research agendas and to be considered within such broader contexts. Most CSCL research should probably not be conceived of as isolated technology innovations, self-contained experiments or well-defined theoretical insights, but as contributions to a larger effort to transform education, using networking technology as a lever.

\section{Lesson 5: Leverage technological advances}

CSCL began with the recognition of the potential of computer technology to bring people together in new ways and to support their learning together. So computational, digital, networked technology will always play a central role in CSCL research. As new techniques, devices and media become available, they will continue to inspire new educational approaches. The popularity of video games (especially multi-user games that require teamwork and learning), mobile computing, and tabletop devices, ubiquitous access to information, social networking and future technologies suggest new forms for educational software and 
new models for collaboration and learning. But the lesson of the past is that schools are very slow to change and that the promises of past technologies like radio, television and film to transform educational practices did not materialize. To successfully leverage the new technical opportunities will require a deep understanding of existing practices and a careful refining of applications if educational technologies are to enter the classroom effectively without being completely co-opted into the traditional systems.

\section{Lesson 6: It takes a global village}

While educational technology will have to be accepted into one classroom at a time, that acceptance will have to be part of a much larger, well-conceived effort. We still have only relatively vague ideas about what an educational system based on computer-supported collaborative learning would look like. Despite the fact that the world's major software developers have long recognized the importance of software to support collaboration, they have produced only the most primitive tools for working together-and virtually nothing for learning together. Email and texting have little ability to support serious collaboration, yet that is all that most people use. The public's vision of educational software is at least fifty years behind the times, limited to arithmetic drills and the like. Yet all that CSCL can offer is a series of research prototypes and proofs of concept. To build a robust knowledge of how to put the ideals of CSCL into practice will take a global effort of researchers, teacher professional development, school reform and political will. The CSCL field has succeeded in spreading the basic ideas and changing attitudes in certain circles. Successful attempts at a small scale can serve as models for larger transformations. It is clear that CSCL has something extremely important for building the future society and that this is increasingly being recognized around the world. It will take a continuing effort by the global CSCL community working together on the technology, pedagogy, research, theory, policy, training and practice to move significantly forward. The past has laid a rich and intricate basis. The present shows hopeful signs (Chan, 2011; Looi et al., 2011). The future holds promise for achieving some of the opportunities offered by our technological age.

\section{Conclusion}

Focus on a specific project, artifact, intervention or experimental manipulation-but be aware of the multiple dimensions of alternative possibilities and issues. Stay grounded in the specific focus and what you can find in your data, but consider how that data might look with other conceptualizations. Build your argument, but take seriously counter-arguments from other perspectives. Work respectfully with people from different intellectual traditions and invite them to collaborate and bring their approaches to your project. Advances in CSCL will increasingly come from multidisciplinary research labs and from global collaborations.

\section{References}

Barron, B. (2003). When smart groups fail. The Journal of the Learning Sciences. 12(3), 307-359. Barrows, H. (1994). Practice-based learning: Problem-based learning applied to medical education. Springfield, IL: SIU School of Medicine.

Chan, C. (2011). CSCL theory-research-practice synergy: The hong kong experience of implementing knowledge building in classrooms. International Journal of Computer-Supported Collaborative Learning. 6(2)

Cress, U. (2008). The need for considering multilevel analysis in CSCL research — an appeal for the use of more advanced statistical methods. International Journal of Computer-Supported Collaborative Learning. 3(1), 69-84. Doi: http://dx.doi.org/10.1007/s11412-007-9032-2 
Dewey, J., \& Bentley, A. (1949/1991). Knowing and the known. In J. A. Boydston (Ed.), John dewey: The later works, 1925-1953. (Vol. 16). Carbondale, IL: SIU Press.

Dillenbourg, P. (1999). What do you mean by "Collaborative learning"? In P. Dillenbourg (Ed.), Collaborative learning: Cognitive and computational approaches. (pp. 1-16). Amsterdam, NL: Pergamon, Elsevier Science.

Dreyfus, H. (1992). What computers still can't do: A critique of artificial reason. Cambridge, MA: MIT Press.

Gallese, V., \& Lakoff, G. (2005). The brain's concepts: The role of the sensory-motor system in conceptual knowledge. Cognitive Neuropsychology. 21

Habermas, J. (1971). Labor and interaction: Remarks on Hegel's Jena philosophy of mind. In Theory and practice. (pp. 142-169). Boston, MA: Beacon Press.

Habermas, J. (1971/2001). On the pragmatics of interaction: Preliminary studies in the theory of communicative action (B. Fultner, Trans.). Cambridge, MA: MIT Press.

Heidegger, M. (1927/1996). Being and time: A translation of Sein und Zeit (J. Stambaugh, Trans.). Albany, NY: SUNY Press.

Hutchins, E. (1996). Cognition in the wild. Cambridge, MA: MIT Press.

Johnson, D. W., \& Johnson, R. T. (1989). Cooperation and competition: Theory and research. Edina, $\mathrm{MN}$ : Interaction Book Company.

Jordan, B., \& Henderson, A. (1995). Interaction analysis: Foundations and practice. Journal of the Learning Sciences. 4(1), 39-103. Web: http://lrs.ed.uiuc.edu/students/c-merkel/document4.HTM

Kapur, M., \& Kinzer, C. (2009). Productive failure in CSCL groups. International Journal of ComputerSupported Collaborative Learning. 4(1), 21-46. Doi: http://dx.doi.org/10.1007/s11412-008-9059-z

Koschmann, T. (1996a). Paradigm shifts and instructional technology. In T. Koschmann (Ed.), CSCL: Theory and practice of an emerging paradigm. (pp. 1-23). Mahwah, NJ: Lawrence Erlbaum.

Koschmann, T. (Ed.). (1996b). CSCL: Theory and practice of an emerging paradigm. Hillsdale, NJ: Lawrence Erlbaum Associates.

Landauer, T. K. (1996). The trouble with computers: Usefulness, usability, and productivity. Cambridge, MA: MIT Press.

Lave, J., \& Wenger, E. (1991). Situated learning: Legitimate peripheral participation. Cambridge, UK: Cambridge University Press.

Lee, E., Chan, C., \& van Aalst, J. (2006). Students assessing their own collaborative knowledge building. International Journal of Computer-Supported Collaborative Learning. 1(1), 57-87. Doi: http://dx.doi.org/10.1007/s11412-006-6844-4

Looi, C.-K., So, H.-j., Toh, Y., \& Chen, W. (2011). CSCL in classrooms: The singapore experience of synergizing policy, practice and research. International Journal of Computer-Supported Collaborative Learning. 6(1), 9-38. Doi: http://dx.doi.org/10.1007/s11412-010-9102-8

Neill, A. S. (1960). Summerhill: A radical approach to child rearing: Hart Publishing Company.

Papert, S. (1980). Mindstorms: Children, computers and powerful ideas. New York, NY: Basic Books.

Pathak, S. A., Kim, B., Jacobson, M. J., \& Zhang, B. (2011). Learning the physics of electricity: A qualitative analysis of collaborative processes involved in productive failure. International Journal of Computer-Supported Collaborative Learning. 6(1)

Rogoff, B. (1995). Sociocultural activity on three planes. In B. Rogoff, J. Wertsch, P. del Rio \& A. Alvarez (Eds.), Sociocultural studies of mind. (pp. 139-164). Cambridge, UK: Cambridge University Press

Roschelle, J. (1996). Learning by collaborating: Convergent conceptual change. In T. Koschmann (Ed.), CSCL: Theory and practice of an emerging paradigm. (pp. 209-248). Hillsdale, NJ: Lawrence Erlbaum Associates.

Russell, T. (Ed.). (1999). The no significant difference phenomenon. Mindspring Press. Web: http://cuda.teleeducation.nb.ca/nosignificantdifference/ 
Scardamalia, M., \& Bereiter, C. (1996). Computer support for knowledge-building communities. In T. Koschmann (Ed.), CSCL: Theory and practice of an emerging paradigm. (pp. 249-268). Hillsdale, NJ: Lawrence Erlbaum Associates.

Schwartz, D. (1995). The emergence of abstract representations in dyad problem solving. Journal of the Learning Sciences. 4(3), 321-354.

Sfard, A. (1998). On two metaphors for learning and the dangers of choosing just one. Educational Researcher. 27(2), 4-13.

Sfard, A. (2008). Thinking as communicating: Human development, the growth of discourses and mathematizing. Cambridge, UK: Cambridge University Press.

Stahl, G. (2006). Group cognition: Computer support for building collaborative knowledge. Cambridge, MA: MIT Press. 510 + viii pages. Web: http://GerryStahl.net/mit/

Stahl, G. (2008). Book review: Exploring thinking as communicating in CSCL. International Journal of Computer-Supported Collaborative Learning. 3(3), 361-368. Web: http://GerryStahl.net/pub/Sfardreview.pdf Doi: http://dx.doi.org/10.1007/s11412-008-9046-4

Stahl, G. (2009). Studying virtual math teams. New York, NY: Springer. $626+x x i$ pages. Web: http://GerryStahl.net/vmt/book Doi: http://dx.doi.org/10.1007/978-1-4419-0228-3

Stahl, G. (2010). Global introduction to CSCL. Philadelphia, PA: Gerry Stahl at Lulu. 196 pages. Web: http://GerryStahl.net/elibrary/global

Stahl, G. (2011a). How a virtual math team structured its problem solving. Paper presented at the international conference on Computer-Supported Collaborative Learning (CSCL 2011). Hong Kong, China. Web: http://GerryStahl.net/pub/cscl2011stahl.pdf

Stahl, G. (2011b). Theories of cognition in collaborative learning. In C. Hmelo-Silver, A. O'Donnell, C. Chan \& C. Chinn (Eds.), International handbook of collaborative learning. New York, NY: Taylor \& Francis. Web: http://GerryStahl.net/pub/clhandbook.pdf

Stahl, G., Zhou, N., Cakir, M. P., \& Sarmiento-Klapper, J. W. (2011). Seeing what we mean: Coexperiencing a shared virtual world. Paper presented at the international conference on Computer Support for Collaborative Learning (CSCL 2011). Hong Kong, China. Web: http://GerryStahl.net/pub/cscl2011.pdf

Suchman, L. (1987). Plans and situated actions: The problem of human-machine communication. Cambridge, UK: Cambridge University Press.

Vygotsky, L. (1930/1978). Mind in society. Cambridge, MA: Harvard University Press.

Wittgenstein, L. (1953). Philosophical investigations. New York, NY: Macmillan. 